\title{
TRES CONDICIONES DE EMPIRISMO PARA LOS HECHOS DEL LENGUAJE, DE INTERÉS EN UN ENFOQUE COGNITIVO*
}

\author{
Carlos Hernández Sacristán \\ Beatriz Gallardo Paúls \\ Universitat de València
}

\begin{abstract}
RESUMEN
Determinar las condiciones de empirismo de los datos constituye -como es bien sabido- una cuestión clásica de la lingüística. Sin embargo, la respuesta a la misma debe ser renovada en toda aproximación crítica a los paradigmas establecidos o a los métodos concretos de investigación. Este es el caso al menos para la lingüística clínica y para disciplinas próximas como la psicolingüística o la neurolingüística. Asumiendo como presupuesto la dimensión cognitiva del lenguaje, proponemos en este trabajo una nueva versión para tres condiciones de empirismo, claramente diferenciables en términos metodológicos y epistemológicos, pero que deben ser tenidas en cuenta de manera conjunta en la asignación de relevancia a los datos lingüísticos. Estas tres condiciones constituyen viejos temas de discusión en la historia de la lingüística. Proponemos aquí su reformulación o ajuste conceptual, teniendo en cuenta los intereses propios de las disciplinas mencionadas. Recientes investigaciones, tanto de base experimental como etnográfica, avalan la propuesta. Nos permitimos denominar estas tres condiciones en los siguientes términos: 1) accesibilidad individual del hecho social; 2) carácter interiorizable o perspectiva de oyente; 3 ) oralidad o procesamiento preconsciente (esto es, procedimental) del lenguaje.
\end{abstract}

Palabras clave: Psicolingüística, empirismo, accesibilidad, interiorización, oralidad.

\section{ABSTRACT}

How to define the empirical conditions for the data under examination has been -as it is well known- a classical question of linguistics. However, the answer must always be revisited within any critical approach to the established paradigms or to the specific research methods. At least, this is the case for clinical linguistics and related disciplines, such as psycholinguistics and neurolinguistics. Taking the cognitive dimension of language as our point of departure, the aim of this paper is to propose a new version of three empirical conditions that can be clearly differentiated in methodological and epistemological terms, but that must be considered

* Este estudio se enmarca en los proyectos de investigación financiados por el Ministerio de Ciencia e Innovación: "Protocolo de análisis pragmasintáctico en afasias. Un estudio de corpus oral" (HUM2007-66074-C02-02) y "Coherencia, cohesión y pragmática textual en situaciones de déficit lingüístico” (FFI2008-02592/FILO). 
jointly when assigning relevance to linguistic data. These three conditions have been often revisited topics of discussion in the history of linguistics. Attending to the interests of the above mentioned disciplines, we propose their reformulation or conceptual adjustment here. Experimental and ethnographic studies support our arguments. The conditions we are referring to are the following: 1) Individual accessibility to social facts; 2) Interiorization or hearer perspective, and 3) Orality or pre-conscious (i.e. procedural) processing of language.

Key Words: Psycholinguistics, empiricism, accessibility, interiorization, orality.

\section{INTRODUCCIÓN}

Reflexionar sobre las condiciones de empirismo de los datos ha sido un tema recurrente de la lingüística tanto teórica como aplicada. Entendemos que se trata de una labor asociada a todo cambio de paradigma en lingüística, pero también a cualquier labor crítica de alcance sobre modelos descriptivos o explicativos, y sobre las técnicas de investigación relacionadas con los mismos. Las consideraciones que siguen, aunque podrían presentar un interés general, se encuentran inicialmente motivadas por razones muy concretas asociadas a labores de análisis y evaluación de la conducta verbal en afasias y otras patologías del lenguaje, actividad que, desde hace varios años, se ha venido desarrollando por el Grupo de Investigación en Lingüística Clínica de la Universidad de Valencia. En nuestro caso ha sido un ámbito aplicado de la lingüística el que nos ha obligado a replantear cuestiones -ciertamente ya clásicassobre el valor empírico de los datos.

No podía ser de otra manera cuando el tema de investigación son las patologías del lenguaje, lo que nos enfrenta de manera crucial con el deslinde siempre discutible entre hechos naturales y culturales para el lenguaje, o entre sus dimensiones formal y funcional, entre otras dicotomías cuya resolución parece necesaria a la hora de asignar relevancia a los datos con los que trabaja el lingüista. La necesidad de retomar una reflexión crítica sobre las condiciones de empirismo se acrecienta aún más dado el carácter interdisciplinar de la investigación en lingüística clínica y el hecho -suficientemente constatado- de que la denotación del término «lenguaje» podría no ser compartida, en aspectos muy significativos, por las diferentes disciplinas implicadas en el estudio de las patologías del lenguaje. Se impone así tratar de aclarar los presupuestos que se comparten (o que no se comparten) para poder definir un marco dialógico realmente fructífero.

El lenguaje (el dato lingüístico) se nos da de muchas maneras: se escribe, se habla en privado, en público, en sueños, para controlar actividades prácticas, se monologa, se cuchichea, se repite lo ya dicho... Su uso es inmediato, como cuando decimos ifuego!, o diferido, como 
cuando interrumpimos un contacto telefónico al saltar el contestador automático, y volvemos a llamar para dejar un mensaje; podemos leer un texto literario, leer un texto litúrgico, o jugar simplemente con el lenguaje. Y todas estas situaciones, y otras muchas en las que podríamos pensar, son relevantes para el procesamiento del lenguaje y para el grado o el modo con el que configuramos formalmente nuestras expresiones. Entrecruzándose con esta variedad de manifestaciones, existen dos modos genéricos, de alguna manera irreductibles entre sí, con los que el lenguaje se nos ofrece a la experiencia: un modo activo y un modo pasivo, esto es, somos hablantes y somos oyentes. También ambas modalidades son relevantes para el procesamiento cognitivo del lenguaje, y para su constitución o emergencia en el ser humano.

El lenguaje podría definirse como una capacidad genérica que cubre potencialmente todas estas modalidades con las que se hace presente a su usuario y, sin embargo, no deja de resultar razonable preguntarse si todas ellas lo representan de igual forma, si los datos que nos ofrecen son útiles de igual forma para describirlo o explicarlo. Debemos asumir, como punto de partida, que todas ellas nos servirán para ilustrar aspectos de la referida capacidad o, al menos, para ilustrar potencialidades definitorias del lenguaje que pueden ser actualizadas en determinados contextos. Seleccionar como fuente de datos tan solo una de ellas o descartar, sin más, alguna es restringir de forma injustificada un ámbito empírico. Sin embargo, debemos reconocer que la selección restrictiva de una fuente de datos suele estar condicionada por los métodos de trabajo o por el instrumental de exploración disponible. Por ejemplo, en el ámbito clínico resulta muy significativa la selección que imponen sobre la fuente de datos verbales tanto las condiciones experimentales asociadas a las técnicas de neuroimagen ${ }^{1}$ como las pruebas comúnmente usadas en la evaluación psicolingüística².

El problema, con todo, no estriba en el hecho de que las técnicas o métodos experimentales impongan restricciones sobre el modo en que los datos se seleccionan. Al fin y al cabo, los datos siempre de alguna forma se construyen; no están dados ahí, como una visión ingenua podría hacernos pensar. El problema estriba en perder conciencia de este hecho y en confundir, por este motivo, toda la realidad empírica del lenguaje con aquella parcela de sus posibles manifestaciones que los métodos o técnicas disponibles para su estudio nos obligan (lógicamen-

${ }^{1}$ Las técnicas de neuroimagen se han limitado en muchos casos a captar efectos neurológicos de operaciones de discriminación auditiva o, en general, de tareas relacionadas con el lenguaje realizadas en silencio por el sujeto de experimentación.

${ }^{2}$ Las condiciones sociopragmáticas propias de una entrevista clínica suelen imponer el uso de materiales desligados de las condiciones naturales más comunes de la praxis lingüística. El test psicolingüístico somete a evaluación la capacidad de realizar determinadas tareas con materiales verbales, pero en menor medida lo que son usos reales del lenguaje. 
te) a seleccionar. Hablaremos en lo que sigue de condiciones de relevancia o empirismo para el dato lingüístico que no excluyen de entrada ninguna de sus posibles fuentes o manifestaciones, o que al menos no las excluyen por razones que hayan sido previamente impuestas por técnicas o métodos concretos de estudio.

Admitido esto último, asumiremos también -con una ya larga tradición teórica- que no todo aspecto o manifestación del lenguaje ilustra de igual forma y en el mismo grado esta capacidad específicamente humana. Ya en el Curso de Lingüistica General la concepción de la «langue» como entidad abstracta o ideal no le impide a Saussure proponer para este objeto, de manera tal vez contradictoria, un tipo concreto de realización psíquica e incluso, en sus propios términos, una «localización» dentro del «circuito» del habla. Nos permitimos recordar aquí los bien conocidos pasajes iniciales del Curso, donde para la captación del objeto «lengua» se asigna preeminencia a la perspectiva del oyente, esto es, a ese modo pasivo en el que se nos ofrece el lenguaje, estableciendo, de paso, otras dicotomías que han merecido extensas y conocidas reflexiones.

En los siguientes apartados nos vamos a referir a tres condiciones de empirismo para el dato lingüístico que asumen como presupuesto general esa dimensión cognitiva que - avant la lettre- atribuía al lenguaje el padre de la lingüística moderna. Más allá de las bien conocidas exigencias de representatividad sociolingüística o de procedencia natural de una muestra de lenguaje (Labov 1972, Sacks 1984, Stubbs 1983, Leech 1992) ${ }^{3}$, nos plantearemos cuáles son las condiciones de empirismo que deben satisfacer los datos cuando se pretende ilustrar y explicar esta dimensión cognitiva del lenguaje (Fernández Pérez 1999), o cuando se asigna a esta dimensión un papel prioritario en nuestra definición del lenguaje. Consideramos esta reflexión como absolutamente obligada para reorientar de manera crítica al menos las técnicas y los métodos de investigación en lingüística clínica.

\section{PRIMERA CONDICIÓN EMPÍRICA: ACCESIBILIDAD INDIVIDUAL} DEL HECHO SOCIAL

Una idea de amplio alcance en la filosofía de Ortega es recogida en el Prólogo para alemanes (retomando lo ya dicho en Meditaciones del Quijote), con las siguientes palabras:

\footnotetext{
${ }^{3}$ Por ejemplo, «A través del estudio directo del lenguaje en su contexto social, el incremento de los datos disponibles aumenta enormemente, y nos ofrece vías y medios para decidir cuál de los posibles análisis es correcto» (Labov 1972, p. 257). «If we use hypothetical-typical versions of the world we are constrained by reference to what an audience of professionals can accept as reasonable» (Sacks 1984, p. 25).
} 
«Tanto la vida social como las demás formas de la cultura se nos dan bajo la especie de vida individual». Esta es la realidad radical. Lo demás es «abstracto, genérico, esquemático», secundario y derivado respecto a la vida de cada cual, a la vida en cuanto inmediatez (cursiva nuestra) (Ortega y Gasset, 1983: 43).

Así lo debemos pensar también, sin duda, para el lenguaje. La realidad social del lenguaje debe hacerse compatible con el hecho de que su dimensión cognitiva no puede, en sentido estricto, trascender los límites del individuo. Si no es en el individuo, ¿dónde situar esa parte del circuito psíquico en la que «una imagen acústica viene a asociarse a un concepto»? Resulta obvio -pero no está de más recordarlo-que la sociedad, como tal, carece de «psiquismo». Hablar de psicología social no puede ser, por este motivo, otra cosa que hablar del modo particular en que lo social se manifiesta psíquicamente en un individuo. La dicotomía entre un ser social y otro individual no parece, en cualquier caso, tan obvia como pudo acaso sugerirle a Saussure la sociología de Durkheim, centrada en el estudio de fenómenos sociales estrictamente supraindividuales.

En realidad, dentro de los estudios sociológicos, el estrecho ligamen entre lo individual y lo social solo llegará a ser captado en toda su potencialidad explicativa a partir de Goffman 1959 y 1971, y en la orientación microsociológica a la que dan origen sus estudios en los años cincuenta del pasado siglo ${ }^{4}$. De esta orientación deriva el método etnográfico (Hymes 1962, Gumperz 1982) en la descripción de los encuentros sociales y, en particular, el análisis conversacional etnometodológico (Garfinkel 1967, Coulon 1987). Solo resolviendo la dicotomía social / individual como propone el método etnográfico (realización individual del hecho social), resulta posible cumplir con al menos una de las condiciones de validez empírica para los datos lingüísticos, la que denominamos justamente «accesibilidad individual del hecho social».

Por el contrario, hipostasiar lo social y considerarlo al margen de su reflejo individual supondría no cumplir con la referida condición: la lengua es ciertamente un hecho social (transindividual), pero que se constituye solo en la medida en que lo social es procesable «a escala individual», solo en la medida en que el hecho social resulta experiencialmente accesible y disponible para un individuo en tanto que tal. Dicho en otras palabras, la naturaleza social del lenguaje debe ser compatible con las capacidades cognitivas de un individuo concreto que lo usa. Entende-

\footnotetext{
${ }^{4}$ No podemos olvidar aquí, sin embargo, un antecedente muy notable en la obra del sociólogo alemán Georg Simmel (1858-1918) y las aportaciones que a este mismo tema realizan las orientaciones fenomenológicas de la sociología desde Alfred Schütz 1932, la teoría de la acción de Talcott Parsons, o el interaccionismo simbólico de la escuela de Chicago, en cuya tradición se inscribe la «Grounded Theory», una de las corrientes pioneras en la exigencia de que el investigador se incluya en la colectividad social del objeto estudiado.
} 
mos, por otra parte, que solo en el dominio de los hechos lingüísticos «accesibles» a la escala individual se manifiestan «originariamente ${ }^{5}$ la naturaleza funcional de una lengua en tanto que sistema sincrónico, y los procesos «intencionales» que constituyen tanto unidades como estructuras de dicho sistema.

Esta idea no es en absoluto novedosa. Está presente en la lingüística al menos desde los Prinzipien der Sprachgeschichte (1880) de Hermann Paul, quien apelaba a la necesidad de tomar al individuo como punto de partida para la explicación de los fenómenos de evolución histórica de las lenguas. Hermann Paul es en realidad tan solo un representante -aunque muy significado- de todo un paradigma de la lingüística en la segunda mitad del siglo xIx. Este paradigma, el de los neogramáticos, toma distancias respecto a visiones previas que habían considerado a las lenguas como objetos dados al margen de sus hablantes reales, e incluso como «sujetos» ellas mismas que «nacían»y «morían». El desarrollo posterior de la lingüística olvida durante un tiempo, parcial o totalmente, este requisito de remisión a la perspectiva del individuo o, lo que es lo mismo, del acto concreto de habla. Y ello sucede incluso cuando se declara a un saber lingüístico sustentado en hablantes-oyentes ideales como parte de la psicología. Sin embargo, ni a la sociedad-como ya hemos dicho-, ni a un hablante-oyente-ideal o a un hablante-oyente promedio cabe atribuir propiamente (esto es, empíricamente) psiquismo. Tampoco cabe atribuir psiquismo a ningún tipo de artefacto o modelo, al menos si por psiquismo entendemos no solo conducta, sino un complejo indisoluble de conducta y experiencia sobre dicha conducta.

Nos adelantaremos a una posible crítica sobre la anterior formulación afirmando, para evitar malentendidos, que adoptar esta perspectiva propia del individuo sobre los hechos del lenguaje no implicará, en absoluto, privar a la ciencia del lenguaje de capacidad de generalización, ni supondrá confundirla con un anecdotario de usos. Muy al contrario, contar con la referida perspectiva es lo que debe guiar todo el proceso de generalización sobre los datos y la formulación de hipótesis que puedan servir para su posterior explicación. Esto es así si nuestro objetivo consiste en captar los hechos del lenguaje en su dimensión cognitiva o siempre que esta dimensión se considere prioritaria sobre otras en la comprensión de la naturaleza del lenguaje. Resulta absolutamente necesario también cuando queremos satisfacer los requerimientos propios de determinados dominios aplicados de la lingüística.

Unas breves consideraciones sobre el nivel léxico nos permitirán concretar lo que decimos. Parece claro que asumir la dimensión cognitiva

\footnotetext{
${ }^{5}$ No estamos negando un «sello» funcional en los productos que constituyen el patrimonio cultural de una lengua, pero diremos que disponen de él solo en la medida en que han sido en algún momento (o pueden llegar a ser) accesibles a escala individual.
} 
sobre los hechos del lenguaje nos exige discriminar entre acervo léxico general asociado «culturalmente» a una lengua histórica ( patrimonio» léxico) y vocabulario disponible o accesible. Se trata, por supuesto, de dos ámbitos dignos de estudio, pero la perspectiva cognitiva debe centrarse en el segundo y, en cualquier caso, no puede mezclarlos. Los estudios sobre vocabulario disponible parten necesariamente de conductas o usos individuales, pero ello no representa -como por otra parte es bien sabido- ningún obstáculo a la hora de realizar generalizaciones o establecer hipótesis útiles, por ejemplo, para el ámbito aplicado de la enseñanza-aprendizaje de primeras o segundas lenguas. A estos intereses didácticos responden los primeros estudios de disponibilidad léxica en español, que debemos a López Morales 1973, 1978.

Para la lingüística clínica, tanto en la faceta de evaluación como de rehabilitación, resulta casi una obviedad afirmar que el objetivo de trabajo es el léxico disponible a escala individual, y sus condiciones de accesibilidad. Cuando a un sujeto -no previamente entrenado para realizar una labor lexicográfica- se le pide que diga durante un minuto nombres de animales, ofrece listas aparentemente idiosincrásicas como la siguiente:

gato, perro, vaca, mariposa, rata, oso, ballena, salmonete, sardina, canario, loro, culebra, sapo, cebra, cocodrilo, rinoceronte, cerdo, puerco, canguro, koala, leopardo, pantera, león, mosca, mosquito.

Poca capacidad de generalización nos ofrece de entrada un material como este. Pero su comparación con otros obtenidos en parecidas circunstancias (cf. para el caso concreto de nombres de animales los resultados del estudio de Gómez Molina 2009) nos permite observar algunas constantes relativas al número de unidades que se consiguen formular, al número de subclases, al número de unidades en cada subclase, y a los criterios generales con los que las subclases se establecen. A estos podríamos añadir también otros factores, como la velocidad de formulación, que sufre algunas alteraciones, siendo más rápida entre unidades pertenecientes a una misma subclase, y más lenta en la transición de una subclase a otra. Esto último resulta revelador del grado en que se manifiesta el efecto facilitador que la evocación de determinadas unidades léxicas puede tener sobre otras. Nos estamos refiriendo a cuestiones que han sido objeto de estudios experimentales en psicolingüística durante varias décadas, y a los que sería imposible referirnos aquí en su detalle.

Lo que nos importa percibir ahora es el hecho de que estos datos, que cuentan con conductas individuales como fuentes de partida, nos obligan a pensar en modelos o criterios de estructuración y categorización del léxico que pueden ser sustancialmente diferentes a los que cabría esperar de una obra lexicográfica, cuyo interés es ofrecer el acer- 
vo léxico culturalmente asociado a una lengua. Pueden ser también muy diferentes a los que nos propone una semántica estructural, que disocia el material léxico de una lengua de sus condiciones de uso. Sin negar la legitimidad de diferentes modelos de aproximación al léxico en función de los diferentes objetivos prácticos o teóricos, debe quedar claro que desde una perspectiva cognitiva y, en particular, desde los intereses propios de una lingüística clínica son ante todo relevantes los datos que derivan de conductas individuales, esto es, que no suman materiales léxicos sin tener en cuenta las condiciones de accesibilidad individual a los mismos. Solo estos datos nos pueden ofrecer patrones reales de contraste respecto a las conductas deficitarias o patológicas. Cuando hablamos de patologías del lenguaje, es obvio -pero tampoco está de más recordarlo- que no son el lenguaje o las lenguas quienes «padecen» (como tampoco «nacen» o «mueren»), sino solo los individuos hablantes. Nos interesa aquí, en particular, la idea manifestada por Helm-Estabrooks y Albert 1994, pp. 125-135, en un conocido protocolo de rehabilitación de la afasia que sugiere, como método genérico de trabajo, observar y analizar las respuestas individuales a los tests de evaluación, a fin de fijar criterios y materiales terapéuticos adaptados al paciente concreto. Todo lo que precede sustenta el interés que, tanto en la evaluación como en la rehabilitación de la conducta verbal patológica, presenta el examen del llamado «caso único».

\section{SEGUNDA CONDICIÓN EMPÍRICA: CARÁCTER INTERIORIZABLE Y PERSPECTIVA DE OYENTE}

Nos centraremos ahora en una condición empírica relacionada con esa modalidad particular de realización psíquica que proponía Saussure a la hora de determinar una perspectiva científicamente relevante sobre los hechos del lenguaje. Nos referimos a ese modo pasivo o receptivo en el que de manera prioritaria se nos ofrecería la lengua o código subyacente al uso lingüístico. Trataremos de aclarar en lo que sigue el alcance de esta afirmación, asumiendo que lo materialmente exteriorizado ni agota, ni se corresponde con lo relevante para el estudio del lenguaje, pero también que lo relevante no debe confundirse simplemente con lo abstracto en un sentido lógico, esto es, con algo dado al margen del uso lingüístico concreto y de las bases cognitivas que lo sustentan. ¿Cuál puede ser ese otro sentido «pragmático» y «experiencial» de lo abstracto? ¿Es el que corresponde a la perspectiva del oyente? Nos preguntamos, de momento, si la dicotomía entre modo activo y modo pasivo con el que se manifiesta el lenguaje no merece una crítica similar a la que merece la dicotomía social / individual. ¿Podemos asimilar, sin más, la posición de oyente a un modo pasivo de relación con el lenguaje? Hay 
muchas razones (cf. sobre este tema Gallardo 1992) para pensar que el oyente no es un mero receptor pasivo del lenguaje, y razones obvias para entender -y constatar- que el hablante es siempre empíricamente el primer oyente de sus palabras ${ }^{6}$. En definitiva, la discriminación entre los modos activo y pasivo tampoco resulta ser tan obvia como inicialmente podría parecer.

Y, sin embargo, seguimos pensando que la originaria intuición saussureana mantiene todo su interés ${ }^{7}$. En realidad, apelar a la posición de oyente a la hora de definir una perspectiva que capte la esencialidad de los hechos del lenguaje es una manera particular de proponer que los datos de interés para el lingüista no son datos brutos tal como pueden ser registrados físicamente, sino que requieren un filtro «normalizador», lo que en términos psíquicos supone una «interiorización» de los productos lingüísticos, un tipo particular de «abstracción» para la que la posición del oyente resulta, sin duda, más destacada que la del hablante. En el origen de una disciplina científica sobre el lenguaje se encuentra, pues, la apelación a un «modo silencioso» de nuestra relación con el lenguaje, un modo receptivo o perceptivo. ¿Quiere decir ello que el objeto "lengua" resulta inaccesible para un sujeto en posición de hablante? Obviamente no, pero diremos que solo en la medida en que el hablante participa también de ese modo receptivo o perceptivo de relación con el lenguaje cuando produce una oración ${ }^{8}$.

Al fin y al cabo, el hablante también evalúa lo dicho y, por este motivo, «no lo dice todo», esto es, discrimina entre lo que dice y lo que calla. La pérdida de esta capacidad discriminatoria se manifiesta en más de un síndrome descrito como patología del lenguaje, y singularmente en la afasia llamada fluente. Podríamos afirmar, en este sentido, que el efecto normalizador o de abstracción requerido para los datos lingüísticos deriva de nuestra capacidad de poner en suspenso una actividad,

\footnotetext{
${ }^{6}$ Cf. para las implicaciones de esta relación entre perspectivas de hablante y de oyente Hernández Sacristán 1985.

7 La pragmática ha incorporado esta perspectiva de oyente en el tratamiento de los datos conversacionales, ya que la consideración de las emisiones en la cadena dialógica obliga a considerar todo hablante como receptor de emisiones previas (Gallardo 1996). Jorques 1995, p. 14, señala la complejidad interna del papel receptivo a partir de las teorías de Berko: «el propio receptor es explicado simultáneamente como sistema potencial de respuesta, como perceptor del estímulo y como su intérprete, siendo a la vez receptor y fuente, pues presupone a esta última».

${ }^{8}$ Las diferentes escuelas de tratamiento de datos dialógicos dan cuenta de esta simultaneidad de roles comunicativos mediante el concepto de estrategia comunicativa; cuando cierto hablante emite un enunciado, se adelanta continuamente a la interpretación que puede hacer el oyente, incorporando tal sentido de manera recesiva: «una estrategia hace referencia a un patrón de decisiones en la adquisición, retención y utilización de la información, que sirve para lograr ciertos objetivos, es decir, para asegurarse de que se den ciertos resultados y no se produzcan otros» (Bruner 1969, p. 130).
} 
esto es, de una virtualidad: la de poder inhibir (y, de esta manera, poder también seleccionar o diferir) el uso exterior del lenguaje. Solo esta capacidad hace posible el diálogo. No es, por tanto, que la lengua se nos dé prioritariamente en el oyente, sino que se nos da en términos de plan ejecutor que puede ser suspendido o diferido (Hernández Sacristán 2006). El oyente actualiza en mayor medida esta virtualidad, pero esta última no deja de estar presente también en el hablante, haciendo que su producción cobre un «valor» del que carecería si la referida virtualidad no existiera ${ }^{9}$. Pensemos que la noción de valor en Saussure implica, en definitiva, una relación entre términos dada in absentia, esto es, una relación contemplada al margen del plano ejecutivo real. Desde este punto de vista, la inhibición, que nos permite contemplar este plano ejecutivo en tanto que plano de ejecución virtual, representa el punto o mecanismo de enlace que neutraliza la oposición entre una actividad pura y una pasividad pura. Este es el motivo profundo por el cual el empirismo en lingüística no puede nunca confundirse con un mero registro positivista de los hechos del lenguaje.

Volviendo a cuestiones relativas al léxico, tal vez sea oportuno recordar aquí uno de los debates más comunes que se le presentan a la lingüística de corpus en el tratamiento y valoración de las frecuencias de uso de las unidades léxicas. Nos referimos a la cuestión del reflejo o efecto subjetivo de la variable frecuencia de uso. Parece probado que el hablante dispone de algún tipo de conocimiento implícito sobre la escala de frecuencia y evita, por ejemplo, el uso de palabras raras en determinados contextos comunicativos, por ejemplo, cuando se habla con un niño o un extranjero. Establecer correlaciones entre frecuencias de uso observadas en corpus y escalas subjetivas de la variable de frecuencia se considera fundamental para diferentes aplicaciones prácticas de la lingüística de corpus y, en particular, para el diseño (correcta dosificación) de materiales de enseñanza de segundas lenguas. Kromer 2003 se refiere de manera explícita a la necesidad de tratar los datos de frecuencia de uso tomando como punto de partida leyes de las relaciones psicofísicas con las que se ha tratado de cuantificar el efecto perceptivo o mental de un estímulo físico. Estas leyes, como la ya clásica de Weber-

\footnotetext{
${ }^{9}$ En cualquier caso todo hablante es siempre, de alguna manera, oyente de lo que formula. Esta circunstancia no es baladí, sino esencial para la constitución de las estructuras del lenguaje, para las que el efecto de retroalimentación es imprescindible. También el oyente es, de acuerdo con la teoría motora de la percepción, un hablante que inhibe un patrón expresivo. El rasgo hockettiano -Hockett 1971 (1958), p. 556- de la retroalimentación puede no ser específico del lenguaje humano, pero sí absolutamente requerido para el mismo. El monológo interior es el uso del lenguaje por el que observamos que un hablante se pone en la perspectiva de un oyente. El sujeto tiende a inhibir la vocalización audible, aunque se sorprende a veces escuchando sus palabras o descubriendo que terceras personas lo oyen. Es sin duda esta interiorización de los efectos retroalimentadores lo que define la especificidad del lenguaje humano.
} 
Fechner, que implica una escala logarítmica como filtro «normalizador» o de «interiorización» del estímulo físico, permitirían según Kromer, con los oportunos ajustes, poner en relación frecuencias de uso observadas (plano ejecutivo puro) con el control subjetivo de la escala de frecuencia (plano ejecutivo virtual).

El debate planteado por la lingüística de corpus, y todavía abierto en sus detalles técnicos, ejemplifica una problemática mucho más general sobre el filtro que debe imponerse en nuestra aproximación a los hechos del lenguaje. Existiría un marco «natural» que justifica de manera genérica la necesidad de dicho filtro y que exige de hecho el efecto de normalización o de «equilibrado» entre perspectivas de hablante y de oyente al que nos hemos referido. Este marco no puede ser otro que la propia actividad dialógica. Las formas del lenguaje son abstractas, pero no tanto en el sentido categorial lógico cuanto en el sentido pragmático que permite poner en relación las perspectivas de hablante y de oyente. La verdadera inteligencia verbal, que constituye el objeto de la evaluación psicolingüística, no se corresponde exactamente con la inteligencia lógica, sino con nuestra capacidad de "leer" en la perspectiva del otro. Se trataría, así pues, de un dominio particular de la inteligencia social. Por este motivo, diremos también que el verdadero efecto normalizador del lenguaje es el que podemos identificar en términos de «normalización dialógica». Dicho en otros términos: el para qué de la abstracción en el lenguaje es constituir unidades que sirvan a un tiempo a las perspectivas de hablante y de oyente, esto es, que sirvan en definitiva para dialogar. La abstracción en el lenguaje no es en este sentido más que un medio particular de adaptación de quien habla a la perspectiva del otro.

Lo que acabamos de afirmar explota hasta sus últimas consecuencias los postulados de la conocida como «teoría de la mente» (Wimmer y Perner 1983; Baron-Cohen, Trager-Flusberg y Cohen 2000). Desde su inicial formulación por Premack y Woodruff 1978 para el estudio de ciertas habilidades «representacionales» incipientes en la conducta de chimpancés, la teoría de la mente ha sido considerada de interés en la evaluación de diferentes ámbitos de la conducta humana patológica, en particular referidos a síndromes asociados al desarrollo. Por «teoría de la mente» se entiende una capacidad genérica cuya adquisición por parte del niño resulta imprescindible para el correcto desarrollo de la conducta social. El tipo de tareas más conocidas con las que se somete a evaluación esta capacidad es aquel en el que la conducta de un individuo se ve, o debería verse, condicionada por su representación de los estados mentales de otros individuos con los que interactúa (las llamadas tareas «de falsa creencia»). De esta manera, la teoría de la mente podría denominarse también «capacidad intersubjetiva» (Rondal 2007). Parece obvio que el lenguaje se encuentra especialmente implicado si no en la emergencia inicial, sí en el posterior desarrollo de la capacidad 
a la que nos referimos. Determinados elementos del lenguaje pueden ser objetos empíricos de gran interés en nuestra evaluación al menos sintomatológica del grado de desarrollo de la misma. Así se propone en Gallardo y Gallardo 2008, y Gallardo 2008, donde se recurre a rasgos lingüísticos propios de una pragmática de la enunciación benvenistiana para evaluar narraciones infantiles y casos concretos diagnosticados de TDAH (Trastorno por déficit de atención/hiperactividad). Todos los elementos del lenguaje que sirven a la expresión o control del marco comunicativo se encuentran directamente implicados en el desarrollo de una teoría de la mente.

Añadiremos aquí que el desarrollo de esta capacidad cognitiva requiere de una modalidad experiencial del lenguaje a la que antes nos referíamos y que resulta fundamental para su constitución como medio de comunicación específicamente humano. Pensemos que la representación de un estado mental ajeno adquiere fácilmente la cualidad propia de un «lenguaje interior», esto es, una modalidad «silenciosa» de nuestra relación con el lenguaje. Nos atreveríamos de hecho a proponer que el acceso a un «lenguaje interior» deriva «especularmente» antes de la necesidad de representar estados mentales de otros sujetos con los que se interactúa, que de la necesidad de representar estados mentales propios para satisfacer una función autorreguladora. Y no negamos con ello el interés fundamental que también presenta esta última función en la constitución del lenguaje humano. En cualquier caso, lo implícito, esto es, lo que dejo de decir, es lo que de alguna manera yo ya sitúo en la mente del otro. O dicho a la inversa, lo que infiero como oyente es lo que el hablante dejó en su mente sin decir o, tal vez, no quiso decir. Parece claro que desde una perspectiva cognitiva y, en particular, desde la perspectiva clínica el dato relevante para el lenguaje trasciende en más de un sentido la materialidad objetiva con la que se nos ofrece.

Expresando todo lo anterior de manera sintética, la segunda condición de empirismo asume que lo relevante en un producto E (exteriorizado) del habla es que satisfaga también la perspectiva de un oyente que lo complementa, que satisfaga su condición de producto I (interiorizable), siendo la inhibición el proceso que explica este tránsito (de E hacia I). Entendemos por normalización o abstracción del producto el hecho de que sirve a un tiempo para las perspectivas de la ejecución y la recepción (y, tal vez, no mucho más que para eso). En este sentido, nos permitimos generalizar para el conjunto del sistema lingüístico lo establecido por Liberman y otros 1967 sobre la unidad fonema en su conocida como «teoría motora de la percepción»: fonema es una unidad relacional por la que identificamos la imagen acústica de un sonido teniendo en cuenta su imagen motora, y -en buena lógica- también lo inverso. Esta constitución «interiorizada», esto es, «relacional» del len- 
guaje es lo que, en otros términos, subyace al hecho de que un saber sobre el mismo sea, a su vez, constituyente del mismo (López García 1980, pp. 40-46), esto es, rasgo hockettiano de la reflexividad entendido en todo su alcance.

\section{TERCERA CONDICIÓN: ORALIDAD Y PROCESAMIENTO PRECONSCIENTE}

Pasamos ahora al tipo de discriminación en apariencia más fácil de trazar a la hora de determinar las condiciones de empirismo de los datos lingüísticos. Deberemos, sin embargo, detenernos en ella especialmente ya que los términos con los que se define admiten más de una lectura. Nos referimos a la prioridad de las manifestaciones orales del lenguaje sobre sus manifestaciones escritas. Este tipo de asunción ha sido considerada fundamental para el desarrollo de la lingüística científica dentro del marco general de los estudios filológicos. Como es bien sabido, este presupuesto es reconocido de manera explícita por Saussure 1945 (1916), pp. 72 y 79, pero nos permitiremos recordar aquí sobre el tema las palabras del propio Hockett 1971 (1958), pp. 13-14, a quien acabamos de hacer referencia:

El lingüista establece una distinción entre lengua y escritura, mientras que el lego en la materia tiende a confundirlas. Los términos «lengua hablada» y «lengua escrita» sugieren que para este último habla y escritura no son más que manifestaciones diferentes de un mismo hecho. Con demasiada frecuencia se piensa, incluso, que la escritura es, en cierto modo, más básica que el habla. Casi puede decirse que la afirmación contraria es la verdadera.

(...)

En este aspecto se requiere un cambio de orientación que no resulta fácil. Los antiguos hábitos son difíciles de extirpar. Mucho después de haber aprendido el vocabulario técnico adecuado para hablar del lenguaje directamente y no por medio de la escritura se puede todavía cometer errores. Sírvanos de consuelo el saber que la lingüística necesitó muchos centenares de años para efectuar precisamente esa transición.

Resulta relativamente común que en las pruebas de evaluación de capacidades psicolingüísticas las modalidades de expresión oral y escrita o de comprensión oral y escrita sean consideradas justamente como simples canales alternativos con los que se manifiesta el lenguaje. Queda claro, sin embargo, que en la fundamentación de una ciencia del lenguaje el reconocimiento del carácter secundario de la escritura respecto a los productos orales es algo absolutamente requerido.

Desde el momento en que la escritura puede históricamente no existir en tanto que técnica material asociada a una lengua, parece desde luego probado su carácter de código secundario (Ong 1982). Lo que 
puede no existir difícilmente será esencial para definir ese objeto al que, de manera contingente, sirve de expresión. Pero esta es tan solo la percepción más obvia de los hechos: nos sirve para constatar algo, pero no exactamente para explicarlo. Podemos seguir, así pues, preguntando qué aporta, en definitiva, la oralidad al lenguaje para que el producto oral pueda considerarse más relevante que el escrito en tanto que fuente empírica de datos. Las reflexiones que siguen pueden entenderse como orientadas a esclarecer los motivos por los que esos errores a los que se refiere Hockett en la cita precedente pueden persistir. Habría una suerte de puerta falsa por la que el lingüista, tras negar (o renegar) de lo escrito cae de nuevo -tal vez sin apercibirse de ello- en las redes conceptuales de la escritura.

No parece que la respuesta a la anterior pregunta debamos buscarla en el plano de las realizaciones materiales físicas de la oralidad y la escritura. Como tal, el tipo particular de realización física no aporta nada que podamos considerar esencial al lenguaje, siguiendo aquí los propios presupuestos saussureanos y los de la lingüística posterior a Saussure, tanto europea como americana. Afirmando lo anterior, somos congruentes con la segunda condición de empirismo para los hechos del lenguaje, que acabamos de definir como carácter virtual de los mismos, esto es, aquella condición que nos obliga a considerarlos al margen de su ejecución material concreta. La investigación en lenguas de signos de la comunidad sorda nos permite, ya desde hace tiempo, concluir que manifiestan un carácter primario similar al de las lenguas orales, pese a que el medio físico que sirve de expresión es bien diferente en uno y otro caso. $\mathrm{Si}$, por lo que decimos, nuestra óptica en la consideración de los hechos no puede ser la que focaliza la materialidad física de un medio de expresión, obviamente la oposición entre oralidad y escritura deberá buscarse en algún nivel subyacente al de la propia materialidad. No resulta, de hecho, ninguna novedad afirmar, con una ya larga tradición de estudios, que se precisa una distinción entre oralidad / escritura en tanto que técnicas materiales, y oralidad / escritura en tanto que esquemas cognitivos que se ponen en juego diferencialmente en la producción del lenguaje (Koch y Oesterreicher 1990, López García 2008).

Oralidad y escritura serían estrategias cognitivas asociadas «preferentemente» a los productos materiales orales y escritos, respectivamente. Esta relación de «preferencia» justifica, de entrada, que no se busquen nuevos términos para designar las manifestaciones cognitivas de lo oral y lo escrito; la polisemia que adquieren así estos términos parece totalmente justificada. Pero dado que "preferencia» no supone «exclusividad», entenderemos también que las estrategias cognitivas propias de la escritura puedan realizarse oralmente y, viceversa, que las estrategias cognitivas propias de lo oral se realicen por escrito. Esto suele llevar a cierta confusión. Resulta común, por ejemplo, que en la evaluación 
psicolingüística de habilidades de expresión o comprensión oral se manejen productos materialmente orales, pero concebidos mentalmente como escritos. Existirían al menos dos tipos de manifestación diferencial en la producción del lenguaje que nos permiten distinguir oralidad y escritura desde el punto de vista cognitivo. Nos podemos referir a ellos en los siguientes términos:

- Heterorregulación/Autorregulación: La oralidad supone una estrategia comunicativa heterorregulada ${ }^{10}$, esto es, aquella en la que el decir se planifica contando con la intervención cooperativa de un receptor real, que actualiza normalmente su condición de hablante (de hecho, cuando no lo hace, esta actualización se reclama de manera abierta por el interlocutor). La escritura supone sin embargo una estrategia comunicativa autorregulada, en la medida en que el decir se planifica no contando con intervenciones cooperativas reales, sino -a lo sumo- imaginándolas: el receptor es genérico o se manifiesta am Phantasma; la inmediatez que caracteriza a una producción oral queda suspendida en la escritura ${ }^{11}$. En el contexto de una interacción social cara a cara, el hablar hueco, autocomplaciente (esto es, no cooperativo), supondría algo así como «escribir» donde no toca, con el consiguiente efecto amenazante para la imagen social del otro. El cambio de estrategia cognitiva requerido para transitar de oralidad a escritura mentales se nos hace evidente en uno de los ejemplos con los que ilustrábamos en la introducción de este estudio la pluralidad en los modos del decir. Nos referimos en concreto al caso en que, tras esperar la voz de un conocido en una llamada telefónica, salta el contestador automático; en esta situación, el sujeto con el que contábamos como receptor real pasa a ser receptor am Phantasma y, en consecuencia, la planificación heterorregulada a la que intencionalmente apuntábamos pasa a ser planificación autorregulada. Este cambio de estrategia puede requerir un tiempo de procesamiento (por ejemplo, un si-

\footnotetext{
${ }^{10}$ Varias nociones dan cuenta habitualmente del fenómeno aquí denominado heterorregulación: la retroalimentación (feedback), procedente de la ingeniería de la comunicación y la cibernética (Singh 1966) e introducida en el análisis interaccional por los autores de Palo Alto (Watzlawicz, Beavin y Jackson 1967, p. 24); la predictibilidad de los turnos en el análisis del discurso británico (Coulthard 1977, Stubbs 1983); la pertinencia condicional de la etnometodología (Sacks 1984); o las restricciones de encadenamiento de la pragmática dialógica (Trognon 1988; Auchlin 1988). En última instancia, esta confluencia de intenciones comunicativas asegura que el sistema dialógico pueda ser descrito, a su vez, como homeostático.

11 «Unplanned discourse is discourse that lacks forethought and organizational preparation. Planned discourse is discourse that has been thought out and organized (designed) prior to its expression»(Ochs 1979, p 55).
} 
lencio de dilación), o puede incluso llevar a colgar el auricular antes de reiniciar la llamada para dejar un mensaje.

- Carácter Multicanal/Carácter Monocanal: La oralidad puede también considerarse una técnica heterorregulada de la comunicación verbal en otro sentido. Nos referimos al hecho de que el lenguaje verbal se encuentra en este caso complementado, de manera interactiva, por procedimientos semióticos paraverbales o no verbales. Esto es lo que podemos denominar carácter multicanal del procedimiento comunicativo oral. Por contraste, cabe afirmar también que la escritura es técnica autorregulada en el sentido de que carece de (o no presenta en el mismo grado) dicho complemento, lo que le asigna un carácter monocanal; una llamada telefónica priva a una manifestación oral de parte al menos de ese complemento paraverbal, con lo que podría, por definición, caracterizarse como más «escrituraria» que una práctica oral cara a cara.

Queda claro, por lo que afirmamos, que si bien oralidad y escritura en tanto que técnicas materiales representan una oposición dicotómica (bien se habla o bien se escribe), desde el punto de vista cognitivo debemos, sin embargo, pensar en términos de oposición gradual (Koch y Oesterreicher 1990). Pero no es esta la cuestión que centra ahora nuestro interés. Nos seguimos preguntando por las condiciones de validez empírica de los datos lingüísticos. Se ha dicho antes que el carácter material, en sí mismo considerado, no podía considerarse un factor pertinente en la jerarquización de dichas condiciones. Nos preguntamos ahora en qué sentido, una vez situados, casi por obligación metodológica, en el nivel cognitivo, el carácter autorregulado o el monocanal pueden ser, por el contrario, factores relevantes a este efecto.

Teniendo en cuenta el segundo principio de validez empírica, referido al efecto normalizador o principio de interiorización, podría argumentarse que el producto autorregulado y monocanal nos ofrece una muestra depurada de lenguaje verbal, hipotéticamente más representativa de lo «esencial» o «específico» de esta capacidad comunicativa humana, que el producto heterorregulado o multicanal. Esto último explica, en parte, el prestigio tradicional de la escritura, pero también el proceder habitual, y a primera vista contradictorio, de una buena parte de la lingüística científica. Nos volvemos a referir a ese proceder que declara situar en un segundo plano la escritura material, pero no parece, sin embargo, prestar atención al nivel cognitivo en que la escritura también se manifiesta. Como consecuencia de este «descuido", se ejemplifica, entre otros aspectos, la sintaxis de una lengua con productos que podríamos considerar autorregulados y monocanal (aparte de materialmente escritos). En apariencia, la argumentación a la que aca- 
ba de aludirse, que hace a la escritura más representativa del lenguaje que la oralidad, es potente, y podría justificar la referida incongruencia metodológica, comentada también por Biber 1988, p. 7 en los siguientes términos:

Even within structural linguistics, researchers have not been entirely consistent regarding the primacy of speech. In particular, there has been a gap between theory and practice in recent syntactic research. In theory, writing is disregarded as secondary and derivative from speech. In practice, however, speech is also disregarded as unsystematic and not representative of the true linguistic structure of a language.

Debe reconocerse que no es fácil encontrar la razón por la que el carácter autorregulado o monocanal deba restar condiciones de validez empírica a una expresión lingüística. Nos resistimos, por ejemplo, a pensar que los datos que nos aporta una escritura creativa deban considerarse menos relevantes que los datos conversacionales, simplemente por el hecho de que el carácter autorregulado o monocanal domine en la primera. Dicho sea de paso que estos dos rasgos no pueden realizarse nunca plenamente en toda práctica natural del lenguaje. Bastaría con observar el proceso de escritura para entender la necesidad de desdoblamiento que el sujeto implicado en la misma realiza como emisorreceptor (escritor-lector que habitualmente monologa y es por ello también hablante-oyente), o la necesidad de acompañar con gestualidad fónica e incluso kinésica (reales o imaginarias) el proceso de escritura ${ }^{12}$. Si mantenemos, con todo, la idea, aunque sea solo intuitivamente sustentada, de que la oralidad aporta datos empíricos más relevantes que la escritura en nuestra aproximación a la facultad del lenguaje, deberemos estar pensando todavía en alguna otra propiedad asociada a la expresión oral que no sea, propiamente, ninguna de las ya revisadas: materialidad física, carácter heterorregulado o multicanal.

¿Cuál puede ser, pues, esa otra propiedad a la que aludimos? El propio Saussure apunta, de alguna manera, a la misma cuando afirma que el sujeto no es consciente del objeto «lengua», aunque esta atribución de carácter no consciente parece asociarse en Saussure a la naturaleza supraindividual que atribuye a dicho objeto. Podemos, sin embargo, leer entre líneas que los procesos implicados en la constitución de la «lengua» o en su evolución presuponen que una toma explícita de concien-

\footnotetext{
12 En sentido estricto el carácter heterorregulado o multicanal del lenguaje es algo consustancial al mismo, aunque este hecho no invalida la utilidad descriptiva de las oposiciones que estamos manejando. Obliga, eso sí, a reconceptualizarlas entendiendo lo autorregulado o monocanal como pérdida de componentes heterorreguladores o de dimensiones multicanal. Esta pérdida, por lo que decimos, nunca puede ser absoluta. No existe ni un hablante puro (que no sea de alguna manera oyente) ni un lenguaje verbal puro (en el que no participe de alguna manera lo paraverbal).
} 
cia sobre los mismos no se observe. En realidad, asignar preeminencia a la oralidad como fuente de datos para una teoría del lenguaje, equivale propiamente a afirmar que la lengua se nos da básicamente al margen de un saber explícito sobre la misma. Es obvio que para aprender una lengua, esto es, para constituir el esquema mental que rige nuestra actividad comunicativa, no se requiere saber gramatical, pero tampoco un saber declarativo o explícito acerca del lenguaje.

Las relaciones entre el saber declarativo y el que cabe denominar implícito o procedimental son más complejas de lo que podría dar a entender una simple operación de explicitación, por la que lo oculto se hace transparente. Parece probado que las bases cognitivas que sustentan estos dos tipos de saber son diferentes. No se trata, en definitiva, de una misma realidad inaccesible en un caso y accesible en otro a la toma de conciencia. Resulta especialmente relevante una situación común en el sujeto amnésico (con determinado tipo de amnesia) por la que pierde la capacidad de recordar cuando se le pide explícitamente que lo haga, pero que es capaz de recordar cuando no se le reclama abiertamente. Diremos que el sujeto pierde capacidad declarativa de recuerdo, pero no capacidad procedimental, manifestándose esta última como capacidad cognitiva mucho más robusta o menos susceptible de afectación que la anterior ${ }^{13}$. En cualquier caso, y por lo que se refiere al lenguaje, de igual forma que la escritura material resulta una contingencia histórica para las lenguas, el saber declarativo sobre las mismas no es en absoluto algo decisivo para su constitución. Y con ello no estamos negando, por supuesto, todo el valor que debe asignarse a la escritura y al saber declarativo. Está claro que la escritura material, o los usos que se aproximan al carácter autorregulado o monocanal, suponen una participación relativamente mayor del saber declarativo sobre el lenguaje que los usos materialmente orales, o de carácter heterorregulado y multicanal. Dicho a la inversa, es en estos últimos donde el saber procedimental se nos ofrece de manera relativamente más pura. También en ellos se manifiestan de manera preeminente los rasgos de «automatización» y «corporeización» (embodiment) en el uso del lenguaje.

Cabe afirmar tras lo dicho que el rasgo que nos permite identificar, en sentido estricto, la tercera condición empírica de los datos lingüísticos es el saber procedimental con el que se nos ofrece de manera dominante el lenguaje, y ello aun admitiendo que el procesamiento procedimental o la accesibilidad al saber declarativo no se manifiestan de igual forma en diferentes dominios de organización del sistema lingüístico (por ejemplo, en sintaxis y léxico). Pensemos que lo fundamental para la constitución «natural» de una lengua es que la toma explícita

${ }^{13}$ Cf. Froufe 1997, para una revisión exhaustiva de estudios experimentales sobre este y otros muchos casos de disociación entre saber declarativo y procedimental. 
de conciencia, que no podemos negar que se asocie circunstancialmente a su uso, sea normalmente referida a objetivos externos a las propias técnicas del decir (cf. Paradis 1996). Debo focalizar mi atención en otra cosa que no sea el propio decir para que el uso lingüístico sea natural. No estamos afirmando, por supuesto, que una toma explícita de conciencia sobre una técnica del decir no sea posible (o necesaria a determinados efectos), sino tan solo que esta técnica se constituye «funcionalmente»o «intencionalmente» sin requerir para ello la aportación propia de un saber declarativo.

Estar de acuerdo con este punto de vista no es contradictorio con la primera condición empírica anteriormente formulada, según la cual el objeto social lengua debe ser accesible a la experiencia individual. Parece claro que no podemos identificar hecho experiencial con toma explícita de conciencia. Un objeto como el lenguaje, que debe ser accesible a la experiencia individual, pero en cuya constitución no se encuentra implicada una toma explícita de conciencia, es un objeto que se constituye (básicamente) en el estrato mental que debemos denominar preconsciente más que inconsciente, por razones que no parece oportuno desarrollar aquí14 ${ }^{14}$ La perspectiva diacrónica ilustra de manera obvia sobre la naturaleza preconsciente del lenguaje: parábola evoluciona a palabra, paraula, parole, etc., dependiendo de determinadas circunstancias o contextos funcionales, pero la expresión oral del término «parábola» o-más exactamente- su uso preconsciente constituye un prerrequisito del proceso evolutivo, define lo que podemos considerar una condición de posibilidad para el mismo. También en este nivel preconsciente debe resolverse el proceso normalizador o interiorizador que contempla la segunda condición de validez empírica. Normalización o interiorización no exigen pues, tampoco, toma explícita de conciencia sobre el hecho lingüístico.

${ }^{14}$ Como es sabido, el término preconsciente fue acuñado por Freud dentro del marco teórico del psicoanálisis. El uso que aquí hacemos del mismo no se inserta, sin embargo, en este tipo de tradición, sino más bien en la propia de la orientación cognitiva, que no pierde su condición de experimental como puede, tal vez, afirmarse para el psicoanálisis. El preconsciente, por otra parte, es un nivel dinámico de lo experiencial que no centró propiamente el interés de Freud y la escuela psicoanalítica, y que el propio Freud define con cierta ambigüedad en La interpretación de los sueños. Dentro de esta ambigüedad, son de destacar algunas consideraciones de interés que consignamos a partir de Laplanche y Pontalis 1971, pp. 295-296: «Freud relacionó siempre la diferencia entre Ics (inconsciente) y Pcs (preconsciente) al hecho de que la representación preconsciente se encuentra ligada al lenguaje verbal, a las «representaciones de palabras». (...) ¿Qué comprende, en lo vivido por el sujeto y, más especialmente, en la experiencia de la cura, el concepto de preconsciente? El ejemplo que más a menudo se da es el de los recuerdos no actualizados, pero que el sujeto puede evocar. De un modo más general, el preconsciente designaría lo que se halla implícitamente presente en la actividad mental, aunque sin constituir objeto de conciencia; esto es lo que quiere decir Freud cuando define el preconsciente como "descriptivamente" inconsciente, pero accesible a la conciencia, mientras que el inconsciente está separado de la conciencia». 
Nos preguntamos, para concluir esta sección, qué tipo de habilidad cognitiva mediría una prueba basada con exclusividad en usos declarativos o en un procesamiento consciente de los usos lingüísticos. ¿Captará realmente la base cognitiva asociada al procesamiento natural del lenguaje? Entendemos que para satisfacer lo exigido por la tercera condición empírica, tal como acaba de describirse, resulta irrenunciable el uso de materiales obtenidos en los contextos conversacionales comunes. En este tipo de contextos cabe realmente aproximarse a un uso natural del lenguaje, esto es, aquel en el que nuestra atención consciente se desplaza del medio comunicativo en tanto que tal hacia un objetivo externo que asigna motivación a su uso. Ello es, según se ha dicho, lo que hace procedimental y preconsciente el procesamiento del lenguaje. En realidad, el contexto conversacional satisface a un tiempo las otras dos condiciones de empirismo anteriormente referidas. Es obvio que los elementos lingüísticos puestos en juego cumplen con la condición de «accesibilidad individual del hecho social», pero sucede también que la interacción conversacional nos permite someter a estudio ese lenguaje que no se explicita y observar en acción el efecto de «normalización dialógica»o «interiorización». El material conversacional es «natural» por las anteriores razones, y no simplemente porque sea comúnmente observable. Este supuesto preside la labor de nuestro grupo de investigación en lingüística clínica, y es sin duda compartido por otros muchos autores, en el ámbito al menos de la afasiología, desde principios de los años noventa.

\section{Conclusiones}

Las tres condiciones empíricas a las que hemos hecho referencia definen tres perspectivas diferenciables, aunque estrechamente relacionadas entre sí y que deben, en cualquier caso, conjugarse en la delimitación de datos lingüísticos relevantes desde una perspectiva cognitiva. Ninguna fuente de datos se encuentra inicialmente excluida, pero las condiciones de empirismo aquí mencionadas deben servir al menos para jerarquizarlas por lo que a su potencial explicativo se refiere. Cabría igualmente pensar que estas tres condiciones no se sitúan como tales en un mismo plano. El orden en el que se han expuesto y designado (primera, segunda, tercera) presupone un orden lógico (o fenomenológico) de dependencia entre las mismas. Para los hechos del lenguaje la accesibilidad experiencial de un hecho social constituye el punto de partida. Se trataría de una precondición para las otras dos. Interiorización y procesamiento preconsciente mantienen estrechas relaciones de interdependencia, aunque entendemos que interiorización manifiesta prioridad sobre procesamiento preconsciente por lo que se refie- 
re a la constitución de una dimensión cognitiva para los hechos del lenguaje. Aunque de manera simplemente tentativa, proponemos en el siguiente gráfico un esquema que nos permite visualizar estas relaciones de dependencia.

Tres condiciones de empirismo para los datos lingüísticos.

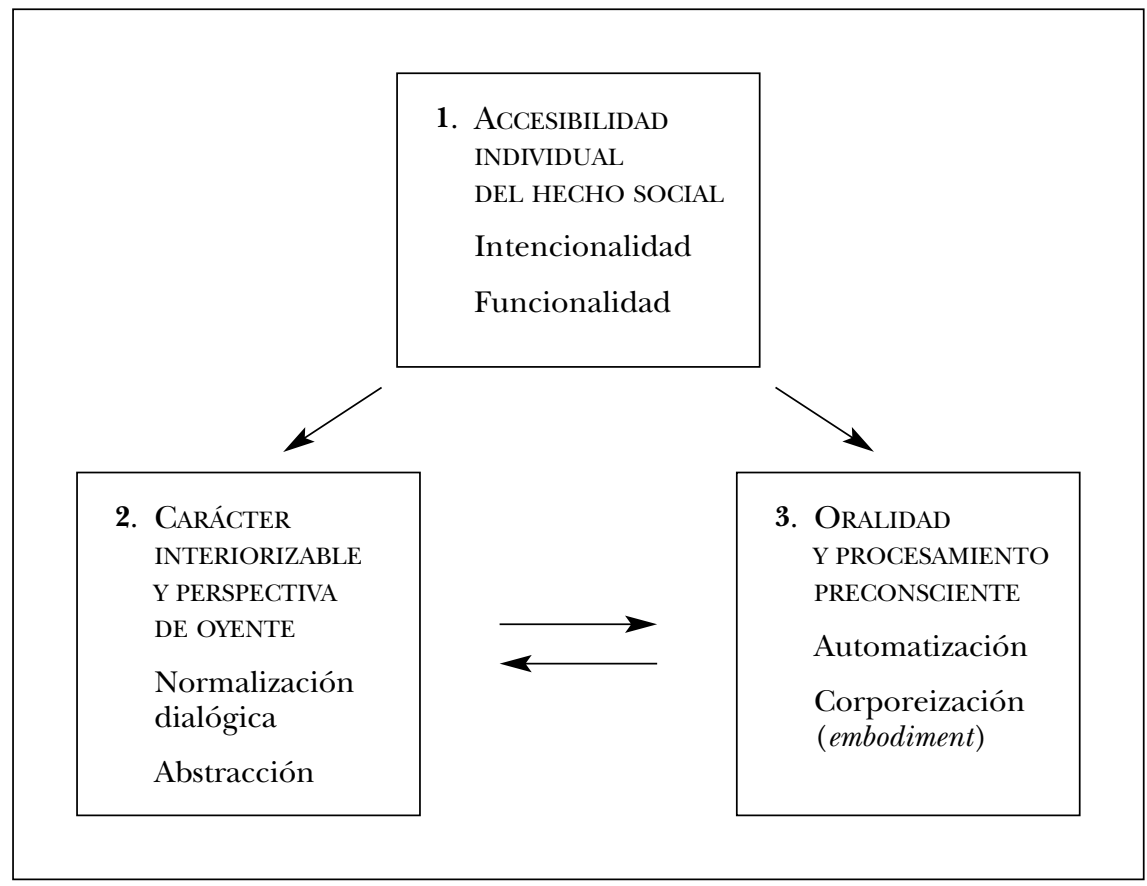

Para concluir debemos referirnos a la naturaleza programática de las afirmaciones precedentes. Las tres condiciones de empirismo sometidas aquí a discusión fijan más criterios orientativos en el estudio del lenguaje, cuando se asume para el mismo un enfoque cognitivo, que criterios cuyo incumplimiento invalide en términos absolutos una investigación metodológicamente fundamentada. Como ya se adelantaba, las técnicas de investigación disponibles pueden exigir un tipo de selección del dato que nos aparta en mayor o menor medida de lo exigido por estas condiciones. Sucede, en cualquier caso, que por su propia naturaleza el cumplimiento de las mismas (o su incumplimiento) admite gradualidad, con lo que su aplicación en términos dicotómicos carece propiamente de sentido. Ello no les priva, sin embargo, del referido valor orientativo sobre técnicas y métodos de investigación o sobre criterios de selección y evaluación del dato. 


\section{REFERENCIAS BIBLIOGRÁFICAS}

Auchlin, Antoine (1988): «Dialogue et strategies: propositions pour une analyse dynamique de la conversation», en Cosnier, J., Gelas, N. y Kerbrat-Orecchioni, C. (eds.), Echanges sur la conversation, París, CNRS, pp. 33-43.

Baron-Cohen, Simon, Tager-Flusberg, Helen y Cohen, Donald J. (eds.) (2000): Understandig other minds. Perspectives from developmental cognitive neuroscience, Oxford, Oxford University Press.

BIBER, Douglas (1988): Variation across speech and writing, Cambridge, Cambridge University Press.

BRUNER, Jerome Seymur (1969): «Orígenes de las estrategias para la resolución de problemas», Acción, pensamiento y lenguaje, Madrid, Alianza Psicología, pp. 129-147 (trad. esp.: Paloma Fernández, 1984).

Coulon, Alain (1987): La etnometodología, Madrid, Cátedra (trad. esp.: Teodora Esteban, 1988).

COUlTHARD, Malcolm (1977): An Introduction to discourse analysis, Londres, Longman, ed. revisada 1985 .

FERnÁndez PÉREz, Milagros (1999): Introducción a la lingüistica, Barcelona, Ariel.

Froufe, Manuel (1997): El inconsciente cognitivo, Madrid, Biblioteca Nueva.

Gallardo PAúls, Beatriz (1992): «Dinamismo conversacional: subsunción y feed-back», Comunicación y sociedad 5, 1 y 2, pp. 51-75.

Gallardo Paúls, Beatriz (1996): Análisis conversacional y pragmática del receptor, Valencia, Episteme, accesible en <www.uv.es/pauls $>$.

Gallardo Paúls, Beatriz (2008): «Las huellas lingüísticas de la teoría de la mente: intersubjetividad y enunciación en el trastorno por déficit de atención/hiperactividad», Revista de Neurología 46, 1, pp. 29-35.

- y Gallardo Paúls, Elena (2008): «Dialogismo en narraciones infantiles», en Díaz, Susana y Goín, Andrea (eds.), Territorios en red. Prácticas culturales y análisis del discurso, Madrid, Biblioteca Nueva, pp. 135-158.

GARFINKEL, Harold (1967): Studies in Ethnomethodology, Englewood, N. J., Prentice Hall.

GofFman, Erving (1971): Relaciones en público. Microestudios de orden público, Madrid, Alianza (trad. esp.: Santos, Fernando, 1979).

- (1959): La presentación de la persona en la vida cotidiana, Buenos Aires, Amorrurtu (trad. esp.: Torres, H. B. y Setaro, F., 1987).

Gómez Molina, José Ramón (2009): «Una aplicación psicolingüística de la disponibilidad léxica: La categoría nocional 'animales'», en Veyrat Rigat, Montserrat y Serra Alegre, Enrique (eds.), La lingüistica como reto epistemológico y como acción social. Estudios dedicados al profesor Ángel López García, Madrid, Arco/Libros, pp. 1047-1060.

GumPERZ, John J. (1982): Discourse strategies, Cambridge, Cambridge University Press.

Helm-Estabrooks, Nancy y Albert, Martin L. (1991): Manual de terapia de la afasia, Madrid, Editorial Médica Panamericana.

HERnÁNDEZ SACRISTÁN, Carlos (1985): «Relaciones de 'subsunción' en la estructura de una lengua natural», Cuadernos de Filología. Teoría: Lenguajes 1, 3, pp. $37-65$. 
Hernández SaCristán, Carlos (2006): Inhibición y lenguaje, Madrid, Biblioteca Nueva.

Hocketт, Charles F. (1971, 1958): Curso de lingüistica moderna, Buenos Aires, Eudeba.

Hymes, Dell H. (1962): «The ethnography of speaking», en Fishman, J. (ed.), Readings in the Sociology of Language, La Haya, Mouton, 1968, pp. 99-138.

JorQues, Daniel (1995): Dimensiones de un análisis de la comunicación y modos de relación interpersonal, Centro de Estudios sobre Comunicación Interlingüística e Intercultural, vol. 3, Valencia, Universidad de Valencia.

Koch, Peter y OesterReICHER, Wulf (1990): Gesprochene Sprache in der Romania: Französisch, Italienisch, Spanisch, Tübingen, Niemeyer.

Kromer, Victor (2003): «A usage measure based on psychophysical relations», Journal of Quantitative Linguistics 10, 2, pp. 177-186.

LABOv, William (1972): Modelos sociolingüisticos, Madrid, Cátedra, 1983.

LAPlanche, Jean y Pontalis, Jean-Bertrand (1971): Diccionario de Psicoanálisis, Barcelona, Labor ( Vocabulaire de la Psychoanalyse, París, Presses Universitaires de France, 1968).

LEECH, Geoffrey (1992): «Corpora and theories of linguistic performance», en Svartvik, J. (ed.): Directions in linguistics: Proceedings of Nobel Symposium 82 (Stockholm, 4-8 de agosto 1991), Berlín, Mouton de Gruyter, pp.105-122.

Liberman, Alvin M., CoOper, Franklin S., Shankweiler, Donald P. y StuddertKennedy, Michael (1967): «Perception of the speech code», Psychological Review 74, pp. 431-61.

LÓPEz GARCíA, Ángel (1980): Para una gramática liminar, Madrid, Cátedra.

- (2008): «Disponibilidad léxica, gramatical y textual», Lingüistica Española Actual XXX/1, pp. 65-86.

López Morales, Humberto (1973): Disponibilidad léxica de los escolares de San Juan, inédito.

- (1978): «Frecuencia léxica, disponibilidad y programación curricular», Boletín de la Academia Puertorriqueña de la Lengua Española 6, 1, pp. 73-86.

OcHs, Elinor (1979): «Planned and unplanned discourse», en Givón, T. (ed.), Syntax and Semantics 12, Nueva York, Academic Press, pp. 51-80.

ONG, Walter J. (1982): Oralidad y escritura. Tecnologías de la palabra, México, Fondo de Cultura Económica (trad. esp.: Scherp, Angélica, 1987).

Ortega y Gasset, José (1983): Prólogo para alemanes. En Obras Completas VIII, Madrid, Alianza Editorial-Revista de Occidente, pp. 11-58.

PARADIs, Michel (1999): «What bilingual aphasia tells us about language processing in the unilingual brain», en Argenter, J. (eds), Language, brain and verbal behavior. Neurobiological aspects of linguistic capacities and language processing, Barcelona, Institut d'Estudis Catalans, pp 77- 85.

Premack, David G. y Woodruff, Guy (1978): «Does chimpanzee have a theory of mind?», Behavioral and Brain Sciences 1, pp. 515-526.

Rondal, Jean (2007): «Teoría de la mente y lenguaje», Revista de Logopedia, Foniatría y Audiología 27, 2, pp. 51-55.

SACks, Harvey (1984): «Notes on methodology», en Atkinson, J. M. y Heritage, J. (eds.), Structures of social action, Cambridge, Cambridge University Press, pp. 21-27. 
Saussure, Ferdinand (1945, 1916): Curso de Lingüistica General, Buenos Aires, Losada (trad. esp.: Alonso, Amado)

SchÜTZ, Alfred (1932): Der sinnhafte Aufbau der sozialen Welt, Viena, Springer.

SINGH, Jagjit (1966): Teoría de la información, del lenguaje y de la cibernética, Madrid, Alianza Universidad (trad. esp.: Garriga Trillo, Ana Julia, 1982).

Stubbs, Michael (1983): Análisis del discurso. Análisis sociolingüistico del lenguaje natural, Madrid, Alianza (trad. esp.: González, Celina, 1987).

Trognon, Alain (1988): «Comment répresenter l'interaction?», en Cosnier, J., Gelas, N. y Kerbrat-Orecchioni, C. (eds.), Echanges sur la conversation, París, CNRS, pp. 19-30.

Watzlawick, Paul, Helmick Beavin, Janet y Jackson, Don D. (1967): Teoría de la comunicación humana: interacciones, patologías y paradojas, Barcelona, Herder, 1989.

Wimmer, Heinz y Perner, Josef (1983): «Beliefs about beliefs: Representation and constraining function of wrong beliefs in young children's understanding of deception», Cognition 13, pp. 103-128. 